\title{
Contribuições e Reflexões sobre o SUS
}

Contributions and Reflections on SUS

Contribuciones y reflexiones sobre el SUS

Maria das Graças Monte Mello Taveira ${ }^{1}$

O livro trata de um sistema de Saude criado há alguns anos, mas que ainda é desconhecido por grande parte da sociedade braisleira. O livro apresenta a história da saúde no Brasil, o arcabouço jurídico, os problemas enfrentados para a saúde publica, as conquistas alcançadas e os desafios presentes e futuros, do Sistema Único de Saúde (SUS) brasileiro.

O livro "O que é o SUS"(1) descreve o Sistema Único de Saúde (SUS) que é o sistema de saúde brasileiro vigente e tem como objetivo maior garantir a saúde das populações e dos indivíduos. Formado por agências que são organizações públicas e privadas, governamentais ou não que promovem, protegem, recuperam e reabilitam a saúde das pessoas e das comunidades e os agentes que são profissionais e demais trabalhadores de saúde que individual e em equipe realizam ações de saúde. $\mathrm{O}$ SUS é ainda entendido restritamente por uma boa parte da população, que o vê apenas pelo atendimento médico, remédio, exames, assistência ofertada nos postos de saúde, não compreendendo o que é um sistema.

A saúde tem sido discutida pelo governo, comunidade, indivíduos e empresa nos últimos tempos, como setor da economia onde se produz bens e serviços. No Brasil, Vários tipos de

${ }^{1}$ Mestre em Ensino na Saúde. Professora Adjunta da FAMED/UFAL. Doutoranda do Programa de PósGraduação de Ciências da Saúde do Instituto de Ciências Biológicas e da Saúde/UFAL. Autora correspondente Campus A. C. Simões. Av. Lourival Melo Mota, s/n. Tabuleiro dos Martins. 57072-900. Maceió, Al, Brasil. E-mail: montegraca@gmail.com Recebido: Abr/2016 - Aceito: Jul/2017. 
serviços desenvolvem as ações de saúde, como: unidades de saúde (postos, centros, hospitais), laboratórios, clínicas, consultórios, centros de zoonoses, centros de reabilitação entre outros. A indústria farmacêutica com meios diagnósticos, material médico cirúrgico e equipamentos atuam como apoio. $\mathrm{O}$ estado sanitário de uma população não depende unicamente dos serviços e ações de saúde e sim de todas as politicas necessárias para o desenvolvimento humano, que devem estar interligadas em sua execução.

O livro traz a historia desde o Brasil Colônia e Império quando tivemos o físico-mor responsável pelo saneamento, curandeiros, benzedeiras, boticários, cirurgiões, médicos.

O cirurgião-mor atendia os militares, sendo a higiene de responsabilidade dos municípios e as Santas Casas atendiam pela filantropia, os indigentes. No início da República a organização dos serviços de saúde era embaraçada, tivemos as campanhas sanitárias que cuidava das doenças endêmicas e epidemias, implantação de instituições cientifica para pesquisa biomédica.

Diante dessa situação foi criado o Departamento Nacional de Saúde Pública que tratava da profilaxia, saneamento, higiene industrial, vigilância sanitária, e controle de endemias. As Caixas de Pensão e Aposentadoria que dava direito aos trabalhadores assistência médica.

Com a evolução das políticas de saúde no Brasil, nosso sistema público de saúde surgiu pela saúde pública, medicina previdenciária e medicina do trabalho, além da medicina liberal, instituições filantrópicas e a medicina popular.

Devido a criticas de como trabalhava a saúde pública, surgiu à proposta de educação sanitária e a criação dos centros de saúde, nesse período foi criado o Ministério da Educação e Saúde. Em 1953 foi instituído o Ministério da Saúde, surgindo órgãos responsáveis pelas campanhas, Serviço Especial de Saúde Público, depois transformado em Fundação Sesp.

No governo de Juscelino foi criado o Departamento Nacional de Endemias Rurais, substituído em 1960 pela Superintendência de Campanhas. Tudo isso funcionava desintegrado da medicina previdenciária desenvolvida pelos institutos, como também da saúde do trabalhador. Com a medicina previdenciária surgiram as Caixas de Aposentadoria e Pensões, em 1930 transformadas em Institutos de Aposentadoria e Pensões.

Em 1960 foram unificados em 
Instituto Nacional de Previdência Social, depois transformado em Instituto Nacional de Assistência Médica da Previdência Social, e sem assistência médica em Instituto Nacional de Seguridade Social. A saúde passou a ser um direito social com a Constituição da República de 1988 através do artigo 196 "A saúde é direito de todos e dever do Estado"(2).

Assim, os princípios organizativos do SUS como regionalização e hierarquização integram ações e serviços em rede, além disso a descentralização dá autonomia aos municípios, financeira e técnica com comando único em cada esfera de governo.

O SUS é gerenciado pelo Ministério da Saúde, Secretarias Estaduais e Municipais de Saúde, desenvolve ações de prevenção, promoção, cura e reabilitação, respaldado pela lei orgânica da saúde, 8080 e a $8.142 / 90$.

Os princípios do SUS (universailidade, equidade, integralidade) são valorizados nas relações sociais que orientam as ações, sendo evidenciados a descentralização e o financiamento e os demais pouco trabalhados. As Diretrizes são orientações organizacionais ou técnicas que propiciam o sistema seguir no mesmo rumo. Implantado em um período de crise econômica que se arrastava desde 1980 com redução de recursos na área da saúde, o que levou ao crescimento da saúde suplementar.

Assim, para ordenar o sistema foram construídas as normas operacionais que dão suporte a organização. Devido essas normas não terem tido a socialização adequada, ocorrem visões diferentes por parte da população, dos técnicos, sindicalistas, gestores, políticos e empresários, interferindo na oferta de serviços,levando muitas vezes a insatisfação por parte dos usuários.

Dentre os desafios do SUS existe o insuficiente financiamento e ainda, recursos humanos pouco qualificados, infraestrutura inadequada, deficiente organização nos três níveis de atenção, pequena resolutividade da atenção básica, dependência do setor privado na média e alta complexidade, judicialização da saúde, crescimento desordenado dos planos de saúde, entre outros.

Esta resenha poderá subsidiar discussões sobre o SUS, (o livro agora está dispinivel on line) $)^{(3)}$ e despertar interesse de estudo, reforçando sua sustentabilidade politica, econômica e cientifica-tecnológica, fortalecendo sua autonomia e reforçando seu caráter republicano e de natureza público.

\section{Referência}


1. Paim, JS. O que é o SUS. Coleção Temas em Saúde. Rio de Janeiro: Fiocruz; 2009.

2. Constituição da República Federativa (BR). Texto constitucional promulgado em 5 de outubro de 1988, com as alterações determinadas pelas Emendas Constitucionais de Revisão nos 1 a 6/94, pelas Emendas Constitucionais nos 1/92 a 91/2016 e pelo Decreto Legislativo no 186/2008. Brasília: Senado Federal, Coordenação de Edições Técnicas; 2016.

3. Paim JS. O que é o SUS. Rio de Janeiro: Fiocruz; 2015: 1-93. Disponível em: http://www.livrosintera tivoseditora.fiocruz.br/sus/4/. 